\title{
Group-Activity Organizing Through an Awareness-of-Others Interface
}

\author{
Douglas Zytko \\ Oakland University \\ Rochester, MI 48309, USA \\ zytko@oakland.edu

\section{Stephen Ricken} \\ New Jersey Institute of \\ Technology \\ Newark, NJ 07301, USA \\ sr82@njit.edu
}

\author{
Quentin Jones \\ New Jersey Institute of \\ Technology \\ Newark, NJ 07301, USA \\ qgjones@acm.org
}

\begin{abstract}
Desires to engage in social group-activities (e.g., pickup volleyball) are common, yet current technologies can leave users hesitant to assume the role of activity organizer because the return they will receive for their efforts is largely unknown. This paper presents a user interface that attempts to reduce barriers to social group-activity organization by informing users of nearby others who share an activity interest and providing tools to facilitate collective action. Preliminary research of the interface indicates a positive association between the visible number of individuals that share an activity interest and one's willingness to initiate organization of the activity. Ongoing research efforts informed by these results are discussed.
\end{abstract}

\section{Author Keywords}

Collective action; group coalescing; social activities

Permission to make digital or hard copies of part or all of this work for personal or classroom use is granted without fee provided that copies are not made or distributed for profit or commercial advantage and that copies bear this notice and the full citation on the first page. Copyrights for third-party components of this work must be honored. For all other uses, contact the Owner/Author.

CSCW '18 Companion, November 3-7, 2018, Jersey City, NJ, USA (c) 2018 Copyright is held by the owner/author(s).

ACM ISBN 978-1-4503-6018-0/18/11.

https://doi.org/10.1145/3272973.3274097

\section{Introduction}

Face-to-face social group-activities (e.g., pickup volleyball, tabletop games) provide benefits to social capital, yet participation in such activities waned through the second half of the 20th century [5]. These activities require collective action $[1,2]$ : a critical mass of individuals with a shared goal. A variety of EventBased Social Network technologies (EBSNs [6]; e.g. Meetup, Eventbrite, Facebook Events) facilitate 


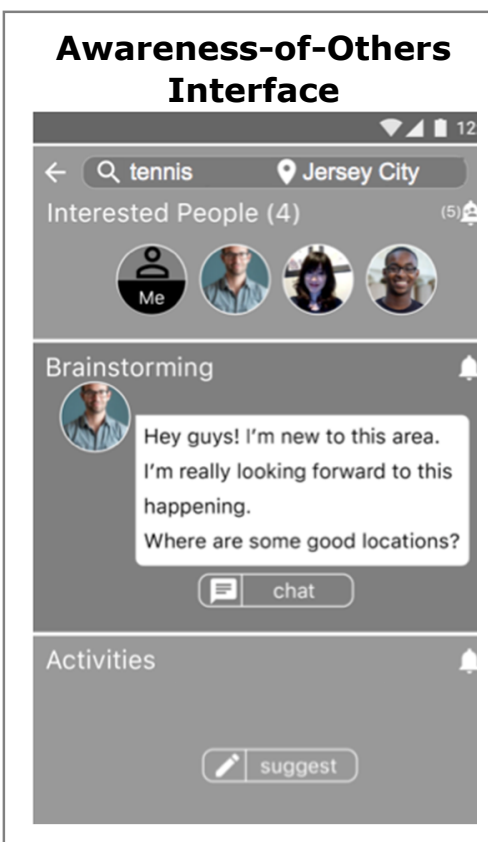

1: Interested People shows other people that have searched for the respective activity in the area.

2: Brainstorming lets users exchange messages with others that share the activity interest.

3: The suggest button lets a user explicitly initiate organization of the activity. collective action by letting users organize, broadcast, and search for activities that interest them. Yet there is evidence that users of these technologies are sometimes hesitant to "step up" and initiate collective action towards group-activity occurrence $[6,7]$. This hesitation largely stems from the amount of work needed to be an activity organizer (e.g., arranging a location and supplies) and unknown returns on efforts to organize (e.g., is there a critical mass of people interested in the activity [4], and will they attend if someone puts in the effort to organize it?) $[6,7]$. This paper presents a user interface that attempts to reduce these barriers to social group-activity organization by informing users of nearby others who share an activity interest and providing tools to facilitate collective action/planning. Preliminary statistics about willingness to initiate activity organization through the interface are reported.

\section{The Awareness-of-Others Interface}

We designed a mobile $U I$ that reflects a use-case in which a user searches for a group-activity interest in a preferred geographic area. The UI depicts the search results page, which has three components that address particular shortcomings in EBSN design (see sidebar). First, current EBSNs do not adequately inform users of nearby others who share a respective interest, barring attendance lists for already-planned activities. Without knowledge of interested others, users are left unsure if a critical mass of participants could be reached, which can diminish their desire to initiate organization. Our UI addresses this with a component called "Interested People" that shows other users that have searched for or expressed interest in doing the respective activity in the specified geographic area (component 1 in sidebar).
Second, current EBSNs poorly facilitate discussion around a group-activity that does not already have an organizer. For example, a user on Meetup cannot demonstrate interest and willingness to assist in organization (which may assuage hesitation from others about becoming an organizer) unless she first organizes an interest-based group by herself. Our UI addresses this with the "Brainstorming" component that lets users view and post messages to others that share an activity interest without any of them needing to first commit to being an organizer (component 2). The UI also includes a call-to-action titled the suggest button, which lets a user explicitly "step up" and initiate organization of the activity by suggesting possible logistics (component 3 ). This call-to-action differs from other EBSNs in that these logistics would not be finalized details of the activity, but rather suggestions that other users/potential organizers could weigh in on and collectively decide.

\section{Hypotheses}

The awareness-of-others interface is being used as a research artifact in a large-scale study to explore various theoretical inhibitors and facilitators of collective action initiation (e.g., critical mass, social facilitation, free-riding). This paper presents an initial exploration of the interface by looking at the general influence that presence of interested people and brainstorming posts have on tendencies to initiate activity organization (i.e., click the suggest button). We hypothesize: $(\mathrm{H} 1)$ There will be a positive association between visibility of interested people and tendencies to initiate activity organization. (H2) There will be a positive association between visibility of a

brainstorming post and tendencies to initiate activity organization. 


\section{Final regression model}

\begin{tabular}{|l|l|l|l|l|}
\hline Predictor & $\mathbf{B}$ & $\begin{array}{l}\text { Wal } \\
\mathbf{d}\end{array}$ & $\mathbf{p}$ & $\begin{array}{l}\text { Exp } \\
\text { (B) }\end{array}$ \\
\hline $\begin{array}{l}\text { Gender } \\
\text { (male) }\end{array}$ &. $\mathbf{3 4 3}$ & $\mathbf{4 . 6 0}$ & $\mathbf{. 0 3 2}$ & $\mathbf{1 . 4 1}$ \\
\hline $\begin{array}{l}\text { Level of } \\
\text { interest } \\
\text { (extremely) }\end{array}$ &. $\mathbf{3 3 7}$ & $\mathbf{4 . 4 3}$ & $\mathbf{. 0 3 5}$ & $\mathbf{1 . 4 0}$ \\
\hline $\begin{array}{l}\text { Organized } \\
\text { before } \\
\text { (never) }\end{array}$ & & $\mathbf{5 6 . 2}$ & $\mathbf{. 0 0 0}$ & \\
\hline $\begin{array}{l}\text { Rarely } \\
\text { Occasionally }\end{array}$ &. $\mathbf{6 6 2}$ & $\mathbf{1 0 . 9}$ & $\mathbf{0 0 1}$ & $\mathbf{1 . 9 4}$ \\
\hline Often & $\mathbf{1 . 6 6}$ & $\mathbf{5 3 . 8}$ & $\mathbf{. 0 0 0}$ & $\mathbf{5 . 2 6}$ \\
\hline $\begin{array}{l}\text { \# of } \\
\text { "Interested } \\
\text { People" } \\
\text { shown }\end{array}$ & $\mathbf{0 2 3}$ & $\mathbf{8 . 5 3}$ & $\mathbf{. 0 0 3}$ & $\mathbf{1 . 0 2}$ \\
\hline Constant & -.455 & 6.16 & .013 & .634 \\
\hline
\end{tabular}

\section{Method}

We conducted an online survey with the group coalescing interface to explore our research questions. Respondents first provided an activity that they "would like to do with a group of strangers near where [they] live, work, go to school, or hang out socially." Respondents entered an activity description and a desired location (e.g., "play tennis at Hamilton Park"), and answered related questions such as how often they had organized and participated in the activity in the (minimum, ideal, and maximum participant numbers).

Respondents were then provided a scenario in which they use a mobile app to search for their respective activity in the desired location. They were presented with the awareness-of-others interface showing search results for the activity/location pair and asked if they would click the suggest button to initiate organization of the activity. Respondents were randomly shown a version of the search results that varied based on visibility of potential activity participants and their willingness to assist in organization, namely: the number of other interested people displayed (ranging from 0 to $1.5 x$ the indicated maximum number of participants) and the presence of a single post in the brainstorming component (the post read, "Hey guys! I'm new to the area. I'm really looking forward to this happening. Where are some good locations?").

Two thousand respondents were recruited through Amazon Mechanical Turk. Of those, 827 (57.2\% female, ages 18-33, from various parts of the United States) were included in analysis after removing entries that were incomplete and/or included nonsensical answers (e.g., a maximum number of activity participants that was less than the minimum).

\section{Results}

Overall, $67 \%$ of respondents ( $71.5 \%$ of men, $63.6 \%$ of women) indicated that they would click the suggest button and initiate activity organization. Types of activities included sports/physical activities, music (e.g., playing instruments together), art/entertainment (e.g., visiting a museum), skill-building activities, discussion groups (e.g., politics), and parties/social gatherings (e.g., pub crawl).

To address our hypotheses, backward elimination logistic regression modeling was performed on the likelihood that respondents would click the suggest button. Control variables included in the modeling were: gender, age, history of participation in the activity, history of organizing the activity, level of interest in the activity, and how many other people one already knows that share the interest. Explanatory variables of interest in the modeling were: a continuous variable for the number of interested people visible (H1) and a dichotomous variable for the presence of a post in brainstorming $(\mathrm{H} 2)$. The final model (see sidebar) was statistically significant, $\mathrm{X}^{2}(6)=$ $85.068, p<.001$. The model explained $13.6 \%$

(Nagelkerke $R^{2}$ ) of the variance in decisions to click the suggest button and correctly classified $68.6 \%$ of cases.

In support of $\mathrm{H} 1$, increasing the visible number of individuals in the interested people section was significantly associated with an increased likelihood of hitting the suggest button. However, the dichotomous variable for presence of a brainstorming post was not in the final model, meaning $\mathrm{H} 2$ was not supported. It was also found that respondents were significantly more likely to click the suggest button if they were male, if they had experience organizing the respective activity 
in the past, and if they were "extremely" (as opposed to just "very") interested in the activity.

\section{Work in Progress}

The preliminary results in this paper suggest that systems may encourage individuals to initiate organization of face-to-face social group-activities by making them aware of individuals nearby that share the interest. However, we found no evidence that demonstrated willingness of those individuals to become involved in the organization process (specifically, a message post inquiring about good locations for the activity) would be additionally encouraging. This could be because potential organizers were more concerned with other people simply showing up to their respective activity than assisting in its planning [17]. It could also be because the single message post utilized in the study had limited value to users (what if there were multiple posts, or posts about logistics that the user was more concerned about?).

Ongoing research with the awareness-of-others interface is exploring how interest in a group-activity should be conveyed to maximize willingness to organize without spurring tendencies to free-ride on the efforts of others. The research builds on this paper's findings by studying theoretical facilitators/inhibitors of collective action pertaining to the specific number of interested people shown in relation to perceived participation parameters (e.g., a critical mass/minimum required number of participants [4], social loafing [3]). Ongoing research is also exploring how activity interest should be visualized (e.g., a message post, evidence of prior attempts by others to organize).

\section{Acknowledgements}

This research is partially supported by a grant from the National Science Foundation 1422696.

\section{References}

1. Richard P Bagozzi and Utpal M Dholakia. 2002. Intentional social action in virtual communities. Journal of interactive marketing 16, 2: 2-21.

2. James S Coleman. 1966. Foundations for a theory of collective decisions. American Journal of Sociology 71, 6: 615-627.

3. Steven J Karau and Kipling D Williams. 1993. Social loafing: A meta-analytic review and theoretical integration. Journal of personality and social psychology 65, 4: 681.

4. Pamela Oliver, Gerald Marwell, and Ruy Teixeira. 1985. A theory of the critical mass. I.

Interdependence, group heterogeneity, and the production of collective action. American journal of Sociology 91, 3: 522-556.

5. Robert D Putnam. 2000. Bowling alone: America's declining social capital. In Culture and politics. Springer, 223-234.

6. Stephen Ricken, Louise Barkhuus, and Quentin Jones. 2017. Going Online to Meet Offline: Organizational Practices of Social Activities through Meetup. In Proceedings of the 8th International Conference on Communities and Technologies, 139-148.

7. Stephen Ricken, Sukeshini Grandhi, Doug Zytko, Starr Roxanne Hiltz, and Quentin Jones. 2014. Anyone for Bowling?: Coalescing for Shared Activities. In Proceedings of the 18th International Conference on Supporting Group Work, 122-130. 